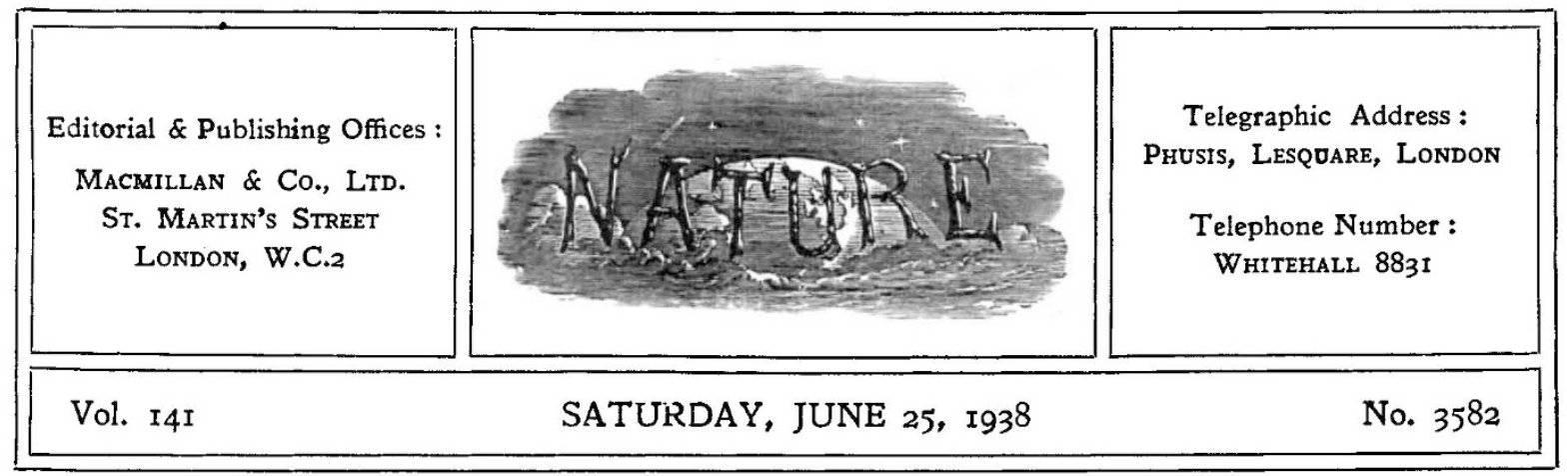

\title{
Prehistory in South Africa
}

$I^{N}$ $\mathrm{N}$ a letter appearing in a recent issue of NaTuRE (June 4, p. 1010) Sir Arthur Keith, commenting on the significance of the Florisbad skull for the study of the origins and distribution of early racial types and its place in the African series of primitive forms of man, drew a remarkable, and at first sight startling, conclusion from a recent examination of a cast of the skull. Pointing, in full agreement, to the anatomical analysis by Dr. Alex. Galloway of the characters of the Florisbad find, from which it appears that Neanderthaloid characteristics are here found accompanying features such as occur in the Boskop skull-a 'modern' type, which Sir Arthur regards as proto-Bushman-he goes on to suggest that not only is Florisbad man a transitional form from Rhodesian man to Boskop man, as Dr. Galloway maintains, but also that he heralds the modern Hottentot and Bushman races of South Africa. The skull is, he says, "a mosaic of Rhodesian, Boskop and Bush characters".

Hence it would appear that Sir Arthur finds in the Florisbad skull a link in the chain of evidence for the theory of the continental evolution of modern racial types, which he put forward some two years ago (see Nature, 138, 194 ; Aug. 1, 1936), and for which he then sought support in the Mongoloid appearances which Prof. F. Weidenreich had detected in the teeth and jaws (and later found in the form of the nose) of Peking man.

It may not be out of place to note in this connexion that even Rhodesian man in certain characters shows an approach to the modern type, in contrast with the primitive facial skeleton-a contrast which moved the late Sir Grafton Elliot Smith to say at first sight that apparently the face was the latest feature to be affected by the evolutionary process. It will be remarked, however, that in the Florisbad skull it is the face, and more especially the forehead, in which the approach to the 'modern' is most marked.

Sir Arthur Keith's letter in NaTuRE, to which reference is made above, should be read in conjunction with the reference to the Florisbad find made by Mr. A. J. H. Goodwin in the course of a survey of recent advances in South African prehistory, which appears in the current issue of Scientia (iii), 32, 1-6; 1938). Mr. Goodwin there points out that the Florisbad skull, which was found in association with extinct animal forms and stone implements by Dr. T. F. Dreyer in 1935 and has been studied by Prof. M. R. Drennan and others, after reconstruction, is the first specimen of a human skull from Africa which may be said to show true Neanderthal characteristics, if $H$. Rhodesiensis be excluded. A further point of importance and great interest, in view of Sir Arthur Keith's conclusions, to which he also refers, is the possibility of a relationship with Prof. Broom's Korana type and the Cape Flats skull. The significance of this will be appreciated if reference be made to the account of the physical characters and culture of the inhabitants of the Oakhurst rock-shelter (see p. 1146 and p. 1151), in which Prof. Drennan finds Hottentot characteristics in the skeletal remains of a people definitely not, or perhaps it should be said not yet, Hottentot in culture. We appear here to be getting very near a chain of positive evidence, with collateral support, for Sir Arthur Keith's independent suggestion that the Florisbad skull, as a transition from the Rhodesian skull to the Boskop type, heralds the modern Hottentot and Bushman races of South Africa. 
A further link in the chain of argument is supplied by an account by Sir Arthur Smith Woodward of a fossil skull of an ancestral Bushman, found on the foreshore of the Blue Nile at Singa, about two hundred miles south of Khartoum (Antiquity, June 1938). He points out that this find is of great interest in view of the fact that it is now recognized that during the Pleistocene, and even during a later prehistoric period, there were in northern Africa human races related to the existing Bushman and the Hottentots of the south; while the shape of the skull in some of the early Egyptians suggests relationship to the Bushman.

This specimen was found in February 1924, by Mr. W. G. R. Bond, then governor of the Fung Province of the Anglo-Egyptian Sudan. It was embedded in a limestone concretion, a few feet above low-river level. It is still partly embedded in the hard matrix, but it has been cleaned enough to exhibit its principal characteristics.

Without entering into the detailed description of the skull given by Sir Arthur, his main conclusions may be mentioned. The skull, it is said, is shorter and wider than the ordinary skulls of Bushmen, but its proportions are not very different from those of a few exceptional examples. It resembles the Bushman, first in the fullness of the frontal region and the slight longitudinal keel in its upper part; secondly, in the flattening of the middle part of the cranial roof; and thirdly, in the prominence of the large parietal bosses and the medium longitudinal depression between them. Other resemblances need not detain us; but the differences are no less important from the point of view with which we are here concerned. For this Singa skull differs from the Bushman in the greater prominence of the supraorbital ridges and in the forward curve of the nasal bones, which indicate a less shortened facial region. It may indeed, Sir Arthur concludes, be regarded as belonging to an ancestral Bushman type, in which the face has not yet shrunken. It is, therefore, especially significant that although Sir Arthur considers that this skull differs from all human skulls hitherto described as found fossil in North Africa, it presents certain resemblances with the skulls found at Afalou-bou-Rhummel in Algeria by Dr. C. Arambourg; but, it is added, in its most important features it agrees still more closely with the Boskop skull, of which it appears to be a brachycephalic variant. The modern Bushman, says Sir Arthur, summing up, may be regarded as a degenerate localized type, with shortened face and protuberant brain-case, of a normalsized vigorous race, once distributed widely in Africa.

To return to the Florisbad skull. Its special interest for the prehistorian lies in the precision with which it can be assigned to a cultural setting. The stone implements, which were found with the skull, of indurated shale, belong to the Middle Stone Age of South Africa. There is present in them, Mr. Goodwin points out, a very clear Mousterian tradition. The most typical form is a flat long triangular point, showing convergent flaking and a faceted butt. With this are later types, backed blades, parallel flakes and so on. Burins also occur. The culture is, in fact, a typical variant of the South African Middle Stone Age.

The special significance of the find in this relation is, as Mr. Goodwin goes on to indicate, that the discovery of Neanderthaloid characteristics in the skull in assoeiation with implements bearing Mousterian stigmata in South Africa is new. Hitherto, the skulls which have been found in certain association with implements of this general group have all belonged to the type of $H$. sapiens; but, he adds, until the chronological relationship between the Florisbad site and other Middle Stone Age deposits has been the subject of more detailed work, it is unfair to draw further conclusions. It may, however, be added that in the survey of the Vaal River gravels, which has been carried out by Dr. R. van Riet Lowe, as summarized by Mr. Goodwin, the Middle Stone Age is associated with the Third Wet Phase after the deposition of the youngest gravels, this being the third and latest of the three series of deposits which have been described. It is, however, significant that in South Africa the Middle Stone Age, though it has its origins in the Mousterian, would appear to have lasted considerably longer than in its European variant, and as it develops shows increasing influence of Upper Palæolithic type. The Later Stone Age diverges still further from any European cultures, and may best be related to the Capsian and later cultures of North Africa.

Lastly, to complete the picture, it may be mentioned that the Oakhurst Rock Shelter (see p. 1151) presents a full history of the local facies of the Later Stone Age, ranging, after the temporary use of the shelter, from Smithfield $B$ cultures to the latest forms in a developed Wilton, the closing phase of Old Stone Age. 